\title{
Efficacy of Current Traction Techniques for Endoscopic Submucosal Dissection
}

Seiichiro Abe ${ }^{1}$, Shih Yea Sylvia Wu $\mathrm{Wu}^{1}$, Mai Ego ${ }^{1}$, Hiroyuki Takamaru ${ }^{1}$, Masau Sekiguchi ${ }^{1,2}$, Masayoshi Yamada ${ }^{1}$, Satoru Nonaka ${ }^{1}$, Taku Sakamoto ${ }^{1}$, Haruhisa Suzuki ${ }^{1}$, Shigetaka Yoshinaga ${ }^{1}$, Takahisa Matsuda ${ }^{1,2}$, Ichiro Oda ${ }^{1}$, and Yutaka Saito ${ }^{1}$ ${ }^{1}$ Endoscopy Division, and ${ }^{2}$ Cancer Screening Center, National Cancer Center Hospital, Tokyo, Japan

This systematic review aimed to assess the efficacy of the current approach to tissue traction during the endoscopic submucosal dissection (ESD) of superficial esophageal cancer, early gastric cancer, and colorectal neoplasms. We performed a systematic electronic literature search of articles published in PubMed and selected comparative studies to investigate the treatment outcomes of tractionassisted versus conventional ESD. Using the keywords, we retrieved 381 articles, including five eligible articles on the esophagus, 13 on the stomach, and 12 on the colorectum. A total of seven randomized controlled trials and 23 retrospective studies were identified. Clip line traction and submucosal tunneling were effective in reducing the procedural time during esophageal ESD. The efficacy of traction methods in gastric ESD varied in terms of the devices and strategies used depending on the lesion location and degree of submucosal fibrosis. Several prospective and retrospective studies utilized traction devices without the need to reinsert the colonoscope. When pocket creation is included, the traction devices and methods effectively shorten the procedural time during colorectal ESD. Although the efficacy is dependent on the organ and tumor locations, several traction techniques have been demonstrated to be efficacious in facilitating ESD by maintaining satisfactory traction during dissection.

\section{(Gut Liver 2020;14:673-684)}

Key Words: Endoscopic submucosal dissection; Traction; Early gastric cancer; Esophageal neoplasms; Colorectal neoplasms

\section{INTRODUCTION}

Endoscopic submucosal dissection (ESD) is a minimally invasive treatment allowing for en bloc resection of superficial gastrointestinal tumors regardless of the lesion size and location. It was initially introduced as an alternative therapeutic option to surgery for early gastric cancer (EGC). ${ }^{1}$ Thereafter this technique has been applied to early esophageal and colorectal neoplasms. ${ }^{2,3}$ For early gastrointestinal neoplasms with negligible risk of lymph node metastasis in Japan and other Asian countries, ESD has been widely accepted as the standard of care as favorable short and long-term outcomes have been reported. ${ }^{4-6}$ As endoscopic expertise expands, ESD is gradually becoming more widespread. On the other hand, ESD is technically demanding and appropriate training is highly recommended to ensure patient safety when performing ESD independently. ${ }^{7,8}$ To date, ESD has been poorly adopted in Western countries, and European Society of Gastrointestinal Endoscopy guidelines proposed ESD should be performed by experts. ${ }^{9}$

One of the reasons contributing to technical difficulty is the lack of traction. During surgical procedure, surgeons are able to access and provide direct traction to the tissue to be dissected. In contrast, endoscopists do not have the benefit of hand-assisted traction during ESD without the use of specific devices and methods. Previously percutaneous tissue traction and magnetic anchor traction were introduced for gastric ESD during 2000s in Japan. ${ }^{10,11}$ However, the former was invasive and challenging in terms of obtaining optimal traction direction, and the latter required a sizable extracorporeal electromagnetic control system not always feasible in an endoscopy room. Similarly, sinker assisted ESD was reported by Saito et al. ${ }^{12}$ However, this device has been less utilized as ESD techniques developed and became more standardized in Japan. Gravity and endoscopic caps are

Correspondence to: Seiichiro Abe

Endoscopy Division, National Cancer Center Hospital, 5-1-1 Tsukiji, Chuo-ku, Tokyo 104-0045, Japan

Tel: +81-3-3542-2511, Fax: +81-3-3542-3815, E-mail: seabe@ncc.go.jp

Received on July 29, 2019. Revised on September 8, 2019. Accepted on October 12, 2019. Published online January 3, 2020.

pISSN 1976-2283 eISSN 2005-1212 https://doi.org/10.5009/gnl19266

@ This is an Open Access article distributed under the terms of the Creative Commons Attribution Non-Commercial License (http://creativecommons.org/licenses/by-nc/4.0) which permits unrestricted non-commercial use, distribution, and reproduction in any medium, provided the original work is properly cited. 
helpful tools routinely used to provide some degree of traction during ESD, but are not always adequate.

Several novel traction devices and strategy have been introduced and developed to facilitate ESD. The aim of this systematic review was to assess the efficacy of the current approach to tissue traction during ESD of superficial esophageal cancer, EGC, and colorectal neoplasms.

\section{METHODS}

In this study, the traction method was defined as novel endoscopic devices and techniques, not including the wellrecognized cap and gravity assisted traction known to facilitate ESD. We performed a systematic electronic literature search for articles on ESD traction methods and techniques published in PubMed from 2000 until May 2019. Two authors (S.A. and S.Y.S.W.) independently participated in the literature search, study selection, and data extraction. The search terms included "endoscopic submucosal dissection" and "traction or tunnel or pocket," and was limited to fully-published comparative ESD studies of the esophagus, stomach, colon and rectum in English and adult human studies. Case reports, single-arm case series, and animal studies were excluded. Moreover, ESD studies of subepithelial neoplasms were also excluded. Using a standardized data extraction form, the following information were collected from each study: patient demographics, the efficacy of the traction technique, and adverse events.

\section{RESULTS}

Using the listed keywords, 381 articles were retrieved. We identified 30 eligible studies in the systematic literature search: five articles of the esophagus, 13 of the stomach and 12 of the colorectum. Seven randomized controlled trials (RCTs) and 23 retrospective studies were included. Of the retrospective studies, propensity matching score analysis was performed in five. There was no disagreement of the literature search between the two authors.

\section{Esophagus}

Esophageal ESD is technically challenging for several reasons. Firstly, the narrow lumen of the esophagus renders gravity countertraction less effective. Secondly, the resected specimen retracts distally during dissection, making it difficult to maintain orientation and adequate traction. Furthermore, the thin wall of the esophagus increases the risk of perforation. ${ }^{13}$ In the systematic literature search, one RCT and four retrospective comparative esophageal ESD studies were included. Three studies investigated the efficacy of clip line traction, and the remaining two articles evaluated endoscopic submucosal tunneling dissection (ESTD) compared with conventional ESD (Table 1). ${ }^{14-18}$

Clip line traction is a simple and an inexpensive technique to

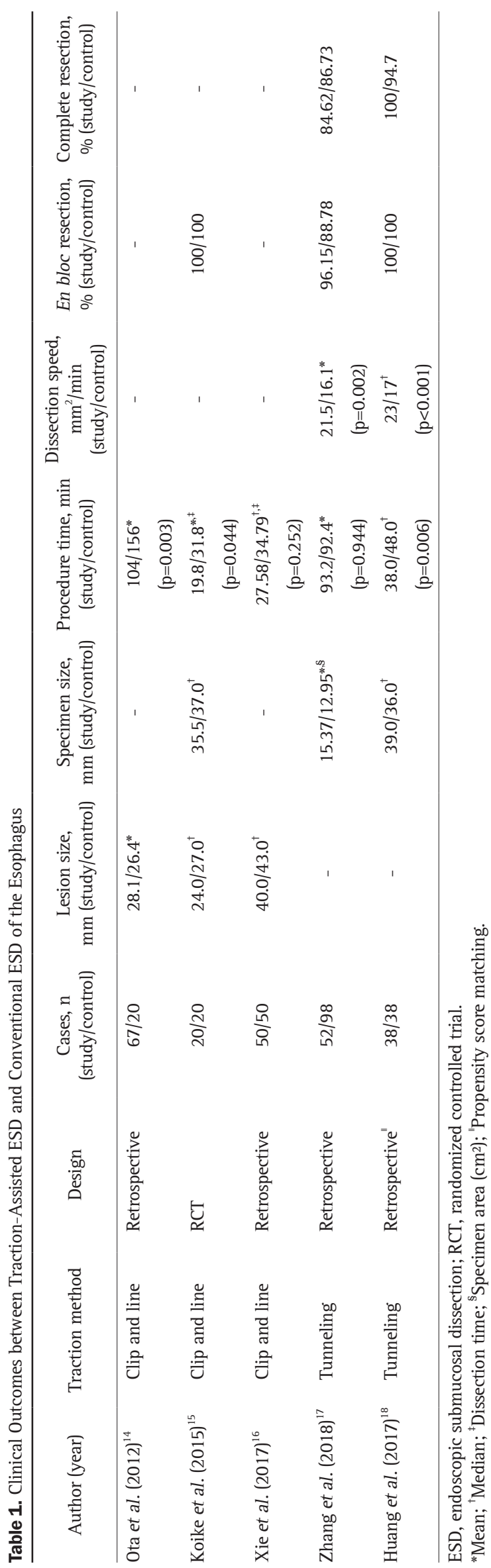


obtain traction during ESD. ${ }^{19}$ An endoclip is inserted through the accessory channel of a gastroscope, and a thread, typically dental floss, is tied to the tip of the endoclip outside the patient. The clip with thread is then applied to the proximal edge of the lesion. The thread is pulled through the mouth proximally and gentle pressure applied to the string, thereby optimizing visualization of the submucosal layer throughout dissection. One RCT by Koike et al. ${ }^{15}$ demonstrated the usefulness of the clip line traction method. In this study, the mean dissection time was significantly shortened in the clip line traction group compared with the conventional ESD group (19.8 minutes vs 31.8 minutes, $\mathrm{p}=0.044$ ). In addition, mean number and amount of local injection during the procedures were significantly reduced in the clip line traction group (0.6 times vs 2.2 times, $\mathrm{p}<0.001$ and $2.6 \mathrm{~mL}$ vs $7.5 \mathrm{~mL}, \mathrm{p}<0.01$, respectively). No adverse events were observed in either group. Moreover, exposure of muscularis propria was less likely to occur in the clip line traction group ${ }^{15}$ Furthermore, both the procedural time in Xie et al. ${ }^{16}$ and the dissection time in Ota et al. ${ }^{14}$ were significantly shorter in the clip line traction group than in the control group, when the extent of the lesion was less than half of the esophageal luminal circumference. Although there was no significant difference between the two groups in terms of the procedural time for lesions exceeding half of the luminal circumference in either study, the sample sizes for the sub-analysis were small in the singlecentered retrospective studies.

ESTD is the technique in which the mucosal incision of the proximal and then distal margins are performed sequentially, followed by making a communication between the two ends dissecting the submucosa proximal to distally. The advantage of ESTD is the ability to achieve a stable scope position inside the tunnel, with improved visualization of the submucosal space due to the effective tissue traction maintained during the procedure (Fig 1). ESTD is indicted for lesions $>20 \mathrm{~mm}$ in diameter and involving at least one third of the esophageal circumference. $^{20}$ A propensity matching analysis by Huang et al. ${ }^{18}$ demonstrated ESTD significantly shortened the ESD procedural time (38.0 minutes vs 48.0 minutes, $\mathrm{p}=0.006$ ) and the submucosal dissection time (30.0 minutes vs 40.0 minutes, $\mathrm{p}=0.005$ ) compared with conventional ESD. In addition, ESTD reduced the rate of muscular injury, although there was no statistical difference in the adverse events. Another retrospective study by Zhang et al. ${ }^{17}$ showed ESTD had a faster dissection speed than conventional ESD $\left(21.54 \pm 13.73 \mathrm{~mm}^{2} / \mathrm{min}\right.$ vs $16.10 \pm 7.53 \mathrm{~mm}^{2} /$ min, $\mathrm{p}=0.002$ ) with similar adverse event rates, although there was no significant difference in the procedural time between the two groups. Moreover, a recent meta-analysis of ESTD, which included the two retrospective studies mentioned above, revealed favorable short-term outcomes. ${ }^{21}$

Although one retrospective study did not show superiority of traction-assisted ESD of the esophagus, traction methods overall were safe and effective in reducing procedural time and avoiding muscle injury during esophageal ESD. Further multicenter RCTs will provide a more definitive conclusion.
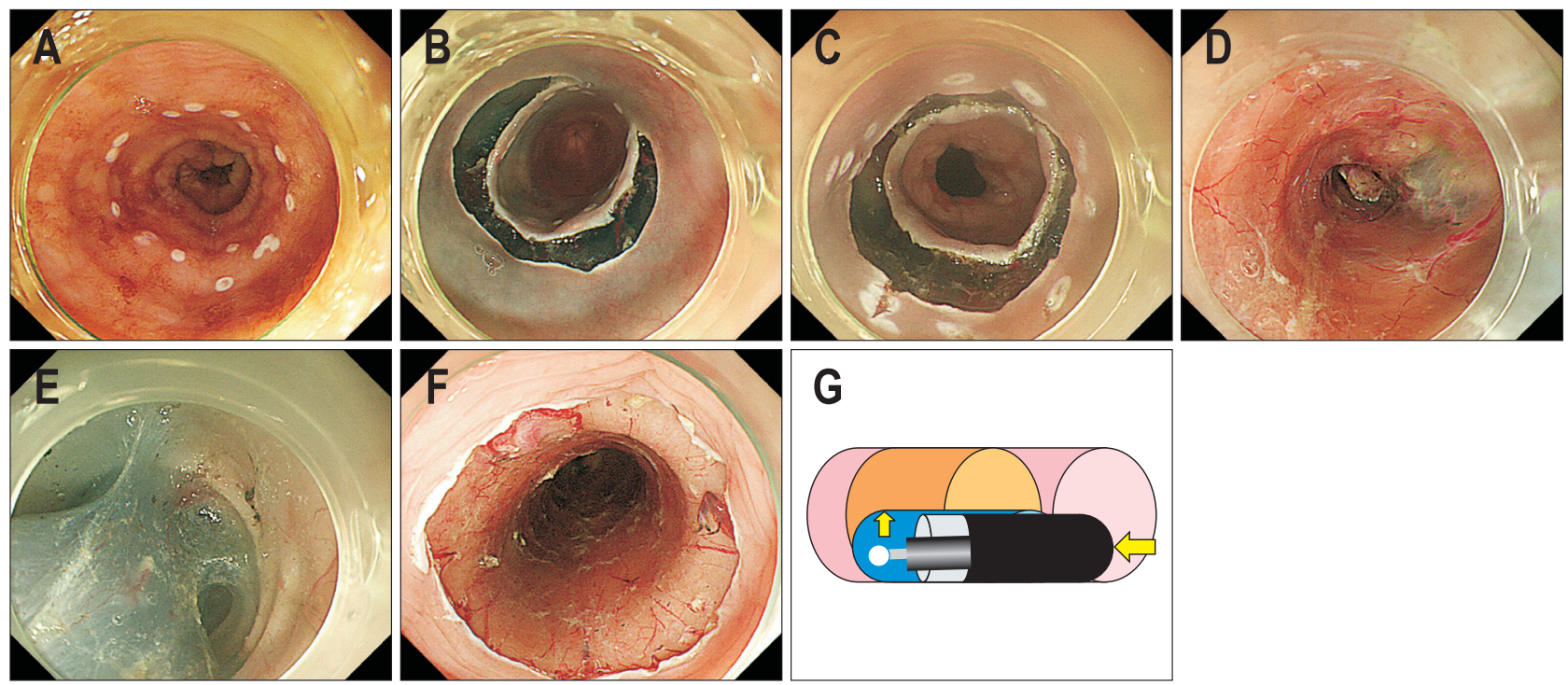

G

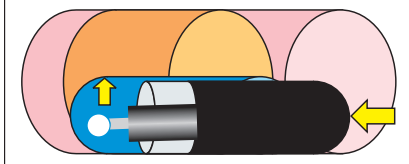

Fig. 1. Endoscopic submucosal tunneling technique of an extensive esophageal squamous cell carcinoma. (A) Markings were performed for a widespread superficial esophageal cancer involving complete luminal circumference in the middle thoracic esophagus. (B) Semicircumferential mucosal incision on the proximal side was performed using a dual knife. (C) Complete circumferential mucosal incision of the distal side to make an endpoint for submucosal dissection. (D) A submucosal tunnel was created with the use of the backside electrode of an insulated tipped nano device. This technique allowed satisfactory tissue traction to be maintained inside the tunnel. (E) After completing submucosal tunneling, submucosal dissection was continued, expanding the tunnel to the lateral side. (F) En bloc resection was achieved. (G) An illustration of endoscopic submucosal tunneling dissection. 


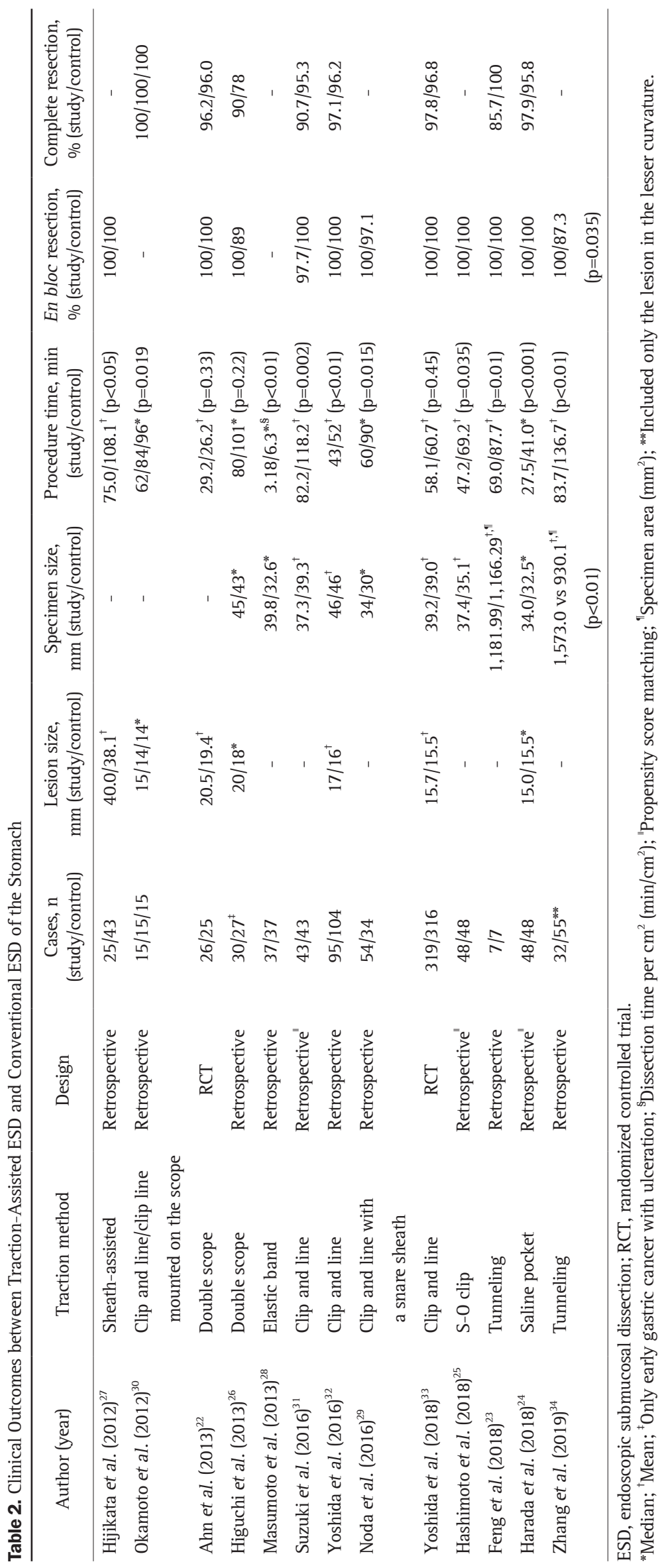




\section{Stomach}

Among the 13 eligible articles of gastric ESD, we identified two RCTs, and 11 retrospective comparative studies. ${ }^{22-34}$ Ten studies compared the efficacy of ESD traction devices, and three other studies investigated the efficacy of traction strategy compared with conventional ESD (Table 2).

Clip line traction, including some modified methods, was the most commonly identified traction device in gastric ESD. Both clips and lines are readily available and inexpensive. Three studies used dental floss because the knot in the dental floss on the clip remains tight and would not loosen. Only minimal mucosal injury may be caused by the dental floss as it is shaped like a flat ribbon, in contrast to silk suture which is thin and cylindrical in shape (Fig. 2). ${ }^{31}$ Based on the results of the two single-center retrospective studies showing dental floss clip (DFC) line traction significantly shortened ESD procedural time compared with conventional ESD, ${ }^{31,32}$ a RCT (CONNECT-G) was conducted. This study included 319 patients undergoing DFCESD, and 316 patients undergoing conventional ESD in the analysis. There was no significant difference in the mean ESD procedural time (58.1 and 60.7 minutes for conventional ESD and DFC-ESD, respectively $\mathrm{p}=0.45$ ). Although the study did not meet the primary endpoint, perforation was significantly less frequent in the DFC-ESD group (0.3\% vs $2.2 \%, \mathrm{p}=0.04$ ). Moreover, sub-analysis showed that for lesions located in the greater curvature of the upper or middle stomach, the mean procedural time was significantly shorter in the DFC-ESD group (57.2 minutes vs 104.1 minutes, $\mathrm{p}=0.01$ ). DFC traction pulls lesions in the direction of the cardia, providing direct, vertical traction force on the mucosal flap lifting it from the submucosa, and allowing appropriate visualization of the dissection line for problematic lesions located in the greater curvature of the upper or middle stomach. ${ }^{33}$
Double scope method was also reported to be effective in reducing the procedural time in ESD of EGC with ulcerative scars. ${ }^{26}$ An RCT of ESD by nonexpert endoscopists was conducted by Ahn et al. ${ }^{22}$ This trial could not demonstrate a significant difference in the ESD procedural time between transnasal scopeassisted ESD and conventional ESD. However, this study only included gastric neoplasms located in the lower third of the stomach for the purpose of ESD training, and it is not possible to conclude double scope method was ineffective based on the result. Other traction devices such as sheath, elastic band, and S-O clip-assisted ESD were also shown to be effective in reducing the procedural time compared with conventional ESD in some retrospective studies. ${ }^{25,27,28}$ In addition, submucosal tunneling technique and water-pocket creation strategy were recently reported to provide efficient traction. ${ }^{23,24,34}$ Among them, Zhang et $a .^{34}$ only included gastric epithelial neoplasms located in the lesser curvature. Furthermore, Harada et al..$^{24}$ demonstrated statistically significant difference in ESD procedural time between water-pocket creation ESD (WP-ESD) and conventional ESD. Interestingly, sub-analysis showed that the median dissection speed in the middle and the lower third of the stomach was significantly faster in the WP-ESD group than in the conventional ESD group. However, the median dissection speed in the upper third of the stomach was not statistically different between the two groups. Although one RCT showed that the traction method was preferred for lesions located in the greater curvature of the upper or middle stomach, the efficacy of traction techniques in gastric ESD depended on the lesion location, the degree of submucosal fibrosis, and the devices and strategy utilized were diverse and varied considerably.

\section{Colon and rectum}

There are reasons unique to colorectal ESD making it a challenging procedure, compared to ESD of neoplasms in other

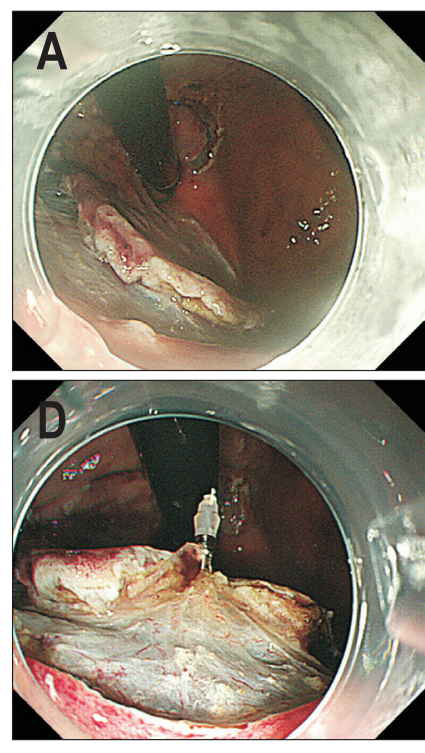

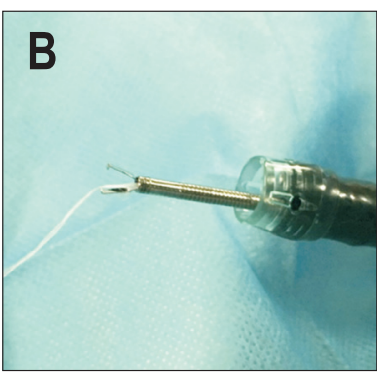
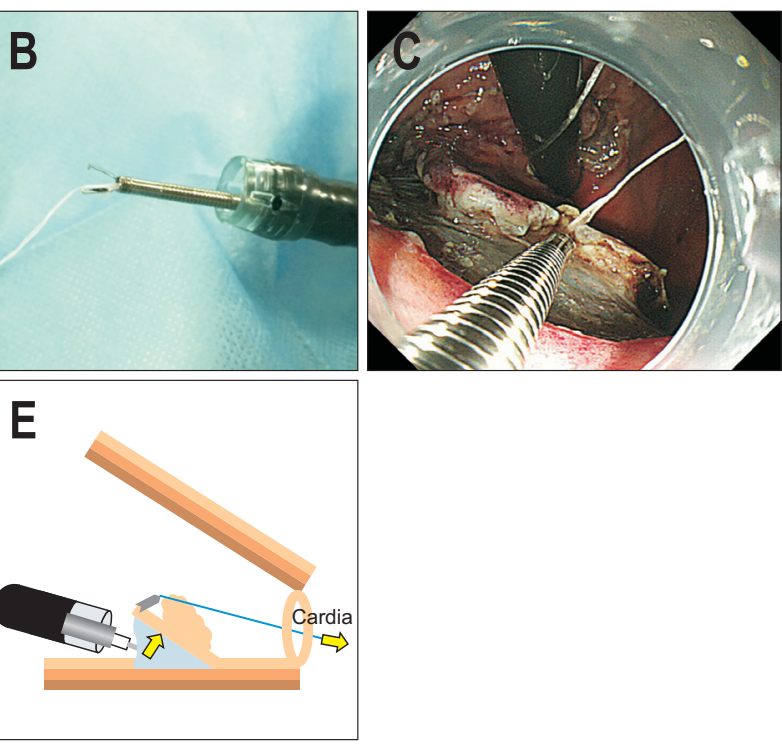

Fig. 2. Clip line traction of gastric endoscopic submucosal dissection. (A) Circumferential mucosal incision was performed for an early gastric cancer measuring $50 \mathrm{~mm}$ in size located in the lesser curvature of the upper gastric body. (B) A line was tied to an endoclip outside the patient. (C) The endoclip with the line was applied to the distal side of the specimen in retroflexion. (D) After pulling the line back proximally, the submucosal plane was well visualized and lifted with sufficient tissue retraction. (E) An illustration of the clip and line traction. 


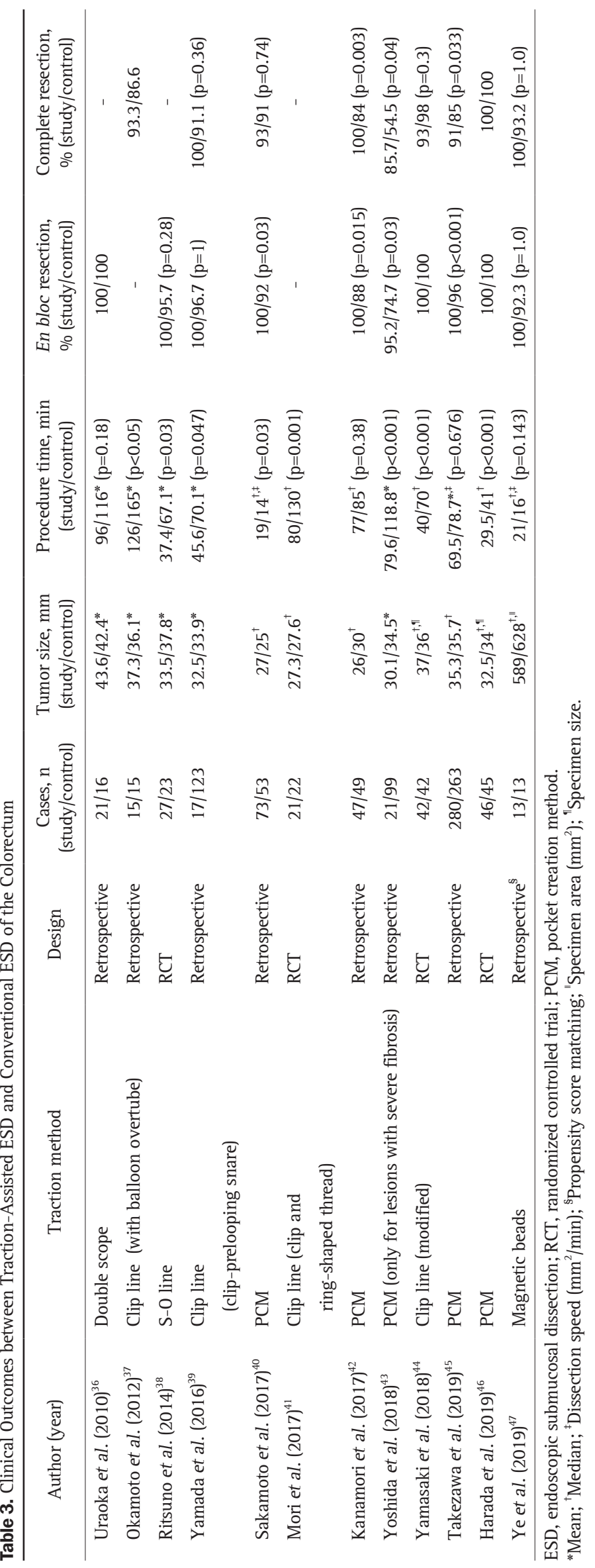


anatomical locations. The thinner colonic walls especially in the proximal colon, the presence of flexures and folds, and peristaltic movements are some of the factors which impact on the ESD procedures. ${ }^{35}$ Along with ongoing refinement of devices and techniques, traction methods have been developed for these reasons. Over the recent few years, the traction methods utilized can be applied to lesions located in any section of the colorectum. Certain former techniques were limited to sigmoid-rectal lesions, ${ }^{36}$ or some required the withdrawal and reinsertion of scope for lesions in the proximal colon. In total, there were four RCTs and eight retrospective comparative studies reporting on traction methods for colorectal ESD fitting the criteria described under the method section (Table 3). ${ }^{36-47}$

As mentioned in the former chapter, clip line traction is regarded as an uncomplicated technique to obtain satisfactory traction. However, it is troublesome during colorectal ESD if withdrawal of the endoscope is required to attach a string to an endoclip outside the patient, before reinsertion and continuing with the dissection. Various modifications to the clip line have been demonstrated to be effective for colorectal ESD, as well as in the stomach. ${ }^{37,39,41,44}$ Yamasaki et al. ${ }^{48}$ described an adapted clip-thread method (TAC-ESD). A string was inserted into the distal end of the accessory channel of a colonoscope beforehand, and pulled back out through the channel using forceps. The ends of the string were tied together outside of the colonoscope. After circumferential mucosal incision, the line was cut and affixed to an endoclip. In this way, one could apply the clip and line without the need to reinsert the endoscope. The author group also conducted a RCT. In this study, colorectal neoplasms $\leq 50 \mathrm{~mm}$ were treated by two endoscopists with intermediate colorectal ESD experience (20-40 previous colorectal ESD), and those $>50 \mathrm{~mm}$ were treated by two experts ( $>200$ colorectal ESD). Procedural time was significantly shorter (40 [11 to 86] minutes vs 70 [30 to 180 ] minutes, $\mathrm{p}<0.001$ ) compared to conventional ESD, with a success rate of 95\%. There was no significant difference in the complication rates between the groups consisting of 42 patients in each arm, although one patient required ileocecal resection for a delayed cecal perforation in the TAC-ESD group. In another RCT by Mori et al., ${ }^{41}$ using a pre-prepared ring-shaped thread, this clip line method was also shown to shorten the dissection time (80 [35 to 130] minutes vs 130 [56 to 240] minutes, $\mathrm{p}=0.001$ ) without any difference in the adverse events. The advantages of this traction method include the fact that it is readily available, cheap, and preparation is straightforward. Furthermore, modifications can be made to the clip line in terms of the devices used, and these adjustments avert the need for reinsertion of the colonoscope, while with other alteration traction points can be added during the ESD procedure as it progressed. $^{39,41,44}$

S-O clip is a novel device designed by Sakamoto et al. ${ }^{49,50} \mathrm{~A}$ 5-mm long spring, which is attached to a metallic clip, with a single nylon loop at its other end, can be mounted on a clip applicator. Via a conventional colonoscope working channel, the clip is firstly applied to the edge of the lesion. Another clip with one its jaw passing through the loop, is then applied to the opposite bowel wall providing effective traction (Fig. 3). In the RCT by Ritsuno et al. ${ }^{38}$ involving 27 S-0 clip-assisted and 23 conventional ESD cases, the S-0 clip-assisted ESD group had a significantly shorter procedural time $(37.4 \pm 32.6$ minutes vs $67.1 \pm 44.1$ minutes, $\mathrm{p}=0.03$ ). Cross-over from the conventional ESD group in $32.8 \%(8 / 23)$ was allowed due to safety considerations, and were performed for lesions located in the bowel flexures including one case located in the caecum. There were no differences in the en bloc resection rates or complications between the two groups.

There were smaller retrospective comparative studies which have devised other traction strategy. Ye et al. ${ }^{47}$ observed that magnetic bead-assisted ESD reduced overall complications ( $0 \%$
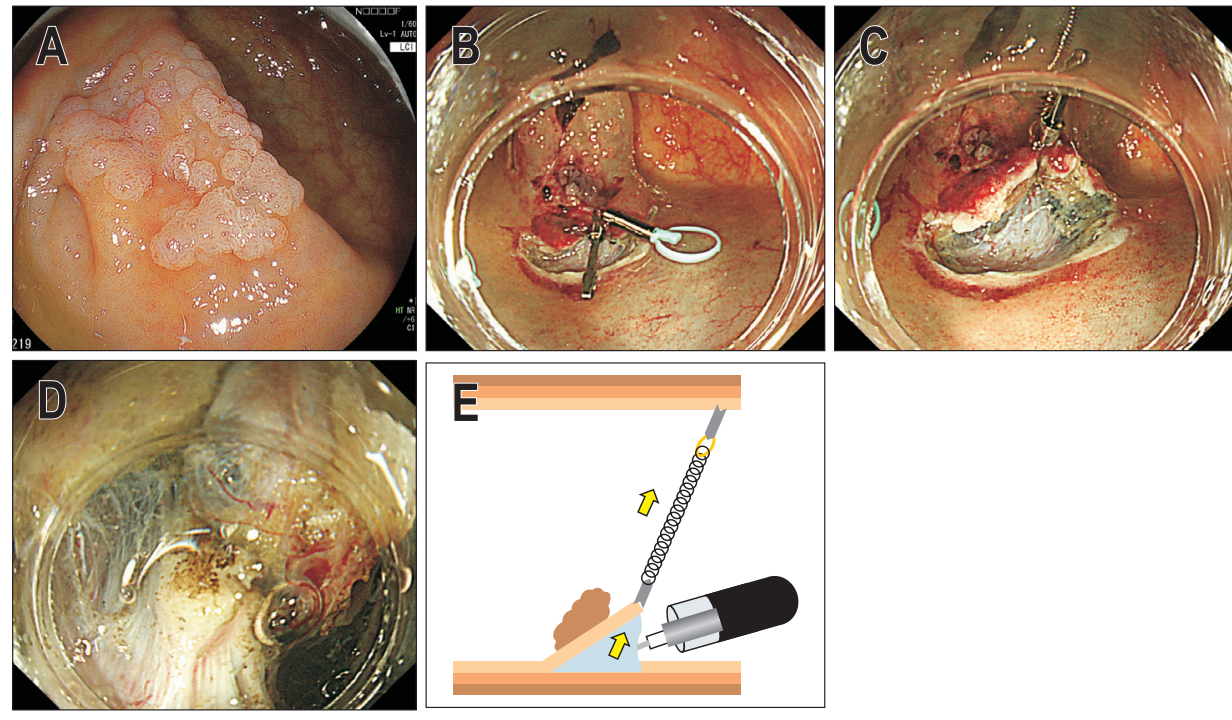

Fig. 3. S-0 clip traction of colorectal endoscopic submucosal dissection. (A) A pale, laterally spreading nodular elevated lesion was observed in the cecum close to the appendix orifice. (B) An S-O clip was applied to the distal side of the specimen after partial mucosal incision. (C) The ring loaded onto the clip was picked up by another endoclip, and the clip was anchored to the opposite side of the lumen. This procedure allowed sufficient tissue traction, and the submucosal space was well exposed. (D) This traction technique facilitated entering the submucosal space. (E) An illustration of S-0 clip-assisted endoscopic submucosal tunneling dissection. 
vs $38.5 \%, \mathrm{p}=0.039$ ) in a propensity score matched analysis, but the dissection time, rates of en bloc and curative resection were similar between the groups. Uraoka et al ${ }^{36}$ described thin endoscope-assisted ESD for sigmoid-rectal lesions. Although there was no statistically significant difference in the resection time, the percentage of cases during which only one electrical surgical knife was used was much higher in the double scope group. The main disadvantage of this method was that it could only be utilized for lower colonic lesions, as there would not be enough working space in the proximal colon.

There were several studies documenting the efficacy of the pocket creation method (PCM). PCM was introduced and developed by the Hayashi and Yamamoto group. ${ }^{51,52}$ In this procedure, a mucosal entry was first created, allowing the endoscope to enter the submucosal space. The submucosal pocket was advanced not only in a forward fashion but also laterally both ways. After creating the pocket, mucosal incision was extended segmentally from the edges of the submucosal pocket (Fig. 4). This method prevents injection leakage, and maintains a stable scope position inside the pocket while sustaining good traction. This approach also allows for tangential scope access even in challenging locations. In the retrospective study conducted by the Takezawa et al., ${ }^{45}$ they demonstrated higher en bloc resection rate $(100 \%$ vs $96 \%, p<0.001)$ and complete resection rate $(91 \%$ vs $85 \%, p=0.033$ ) in the PCM group compared with the conventional ESD group, respectively. The dissection speed in the PCM group was faster $\left(23.5 \pm 11.6 \mathrm{~mm}^{2} / \mathrm{min}\right.$ vs $20.9 \pm 13.6 \mathrm{~mm}^{2} /$ $\min , \mathrm{p}<0.001$ ), while the adverse events were similar for perforation ( $2 \%$ vs $4 \%, p=0.152$ ), and delayed bleeding ( $2 \%$ vs $1 \%$, $\mathrm{p}=0.361$ ). Similar findings were documented by other comparative case series. In the retrospective analysis of 1,000 colorectal ESD cases by Yoshida et al., ${ }^{43}$ severe fibrosis compared to nonfibrotic cases were associated with lower en bloc resection rates
(78.3\% vs 95.7\%, $\mathrm{p}<0.001)$, higher discontinuation rates $(12.5 \%$ vs $0.3 \%, \mathrm{p}<0.001)$, and higher perforation rates $(8.3 \%$ vs $2.6 \%$, $\mathrm{p}=0.001$ ). By utilizing the PCM method, the endoscopists could achieve higher en bloc resection rate $(95.2 \%$ vs $74.7 \%, \mathrm{p}=0.03)$, complete resection rate ( $85.7 \%$ vs $54.5 \%, p=0.04)$, and a shorter mean procedural time $(79.6 \pm 26.5$ minutes vs $118.8 \pm 71$ minutes, $\mathrm{p}=0.001$ ) without discontinuation even in the cases of severe fibrosis. There were no cases of perforation in the PCM group for both fibrotic and non-fibrotic cases, although the differences in complications rates did not reach statistical significance.

Harada et al. described modification of the PCM by filling the pocket with saline instead of carbon dioxide $\left(\mathrm{CO}_{2}\right)$ insufflation (saline immersion ESD). This strategy allowed clearer endoscopic view and better visualization of the dissection line. In addition, due to the tangential dissection plane in colorectal ESD, the saline injected can be easily secured in the created pockets. Based on the safety and efficacy of the saline-pocket method in gastric neoplasm, an RCT was conducted for colorectal lesions. In this study, the procedural time was significantly shorter in the saline-pocket group (SP-ESD) compared with $\mathrm{CO}_{2}$ insufflation group (S-ESD) (29.5 minutes vs 41.0 minutes, $\mathrm{p}<0.001$ ). Subgroup analysis showed the dissection speed of SP-ESD method was faster for LST-NG lesions, cases with fibrosis, and right and left colon but not in the rectum. ${ }^{46}$ The utilization of salinepocket modification may be advantageous in the proximal colon (except in the caecum where perpendicular approach of the endoscope impedes the insertion of scope into the submucosal pocket), and for fibrotic lesions, although larger randomized studies will consolidate this finding.

All colonic ESD studies were single-centered, and further multicenter trials are warranted to examine the generalizability and applicability of these results.
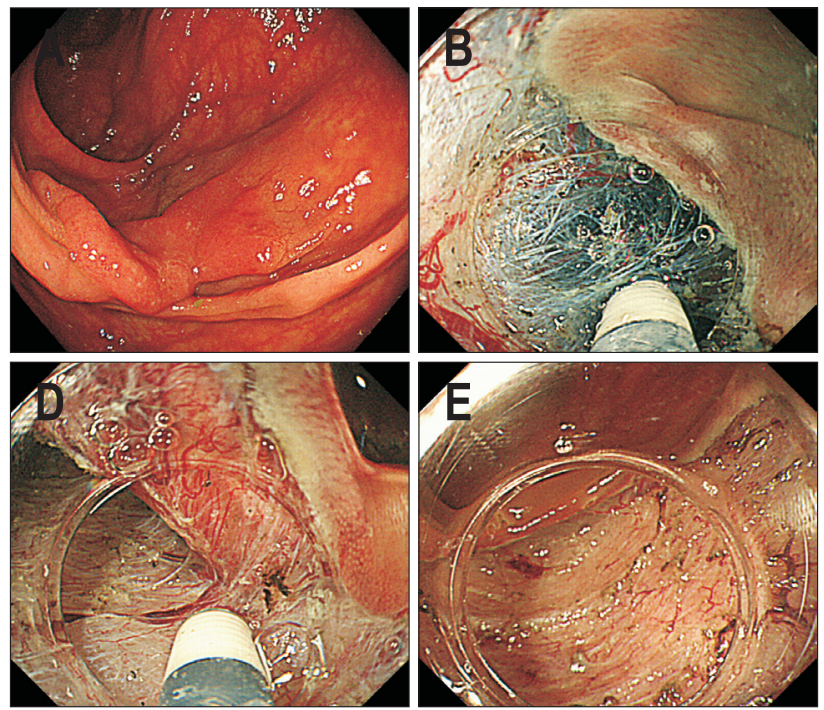

Fig. 4. Pocket creation method in colorectal endoscopic submucosal dissection. (A) A laterally spreading reddish elevation was observed in the transverse colon. (B) Mucosal entry was created by dissecting the submucosa and opening the submucosal space. (C) A submucosal pocket was created by dissecting the submucosa both laterally and proximally. This procedure allowed stable scope position and sufficient tissue traction inside the pocket. (D) Circumferential mucosal incision was performed along the edge of the pocket. (E) En bloc resection was achieved. (F) An illustration of the pocket creation method. 


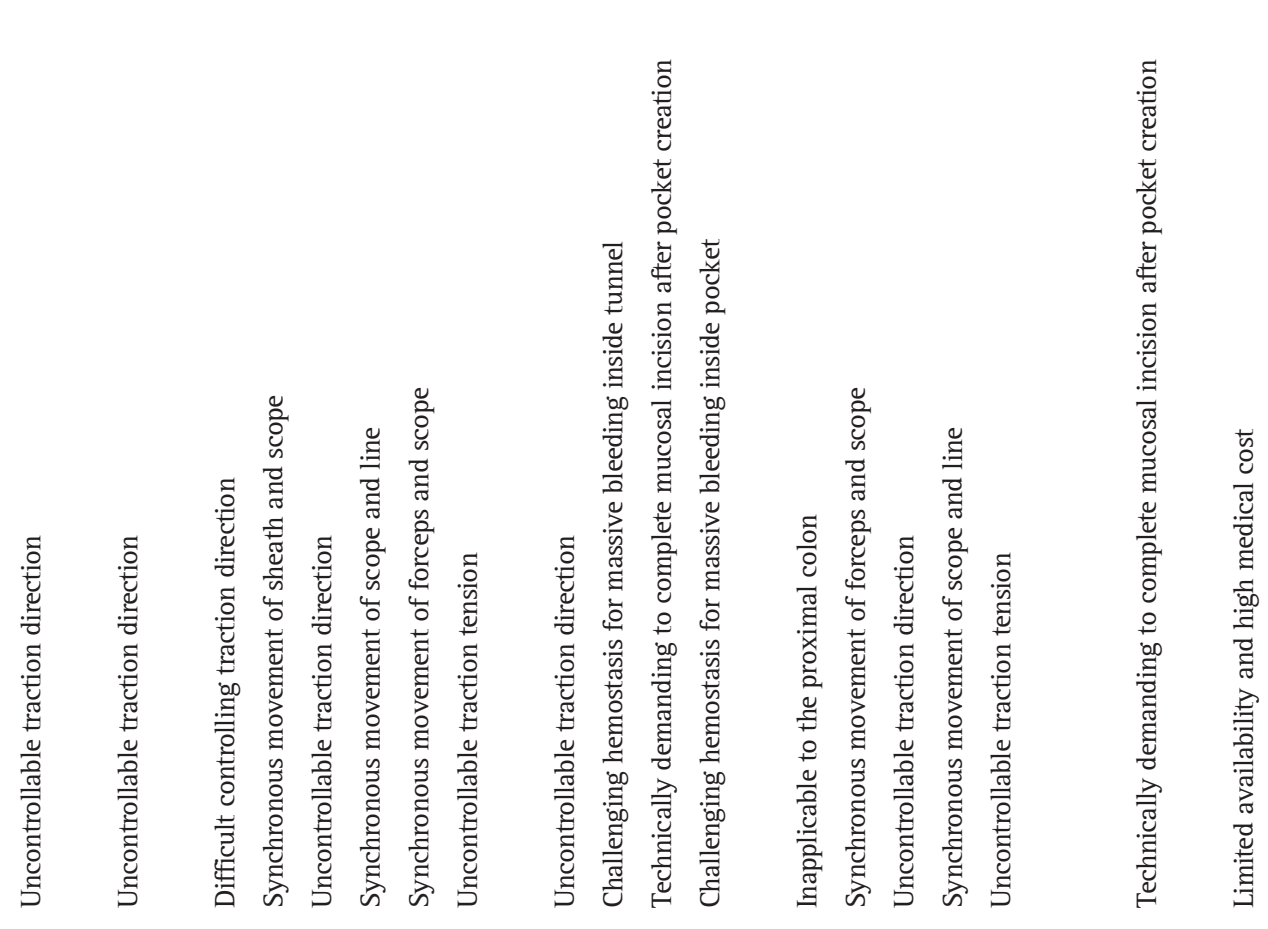

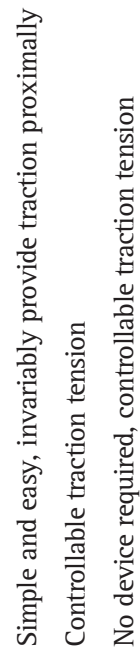

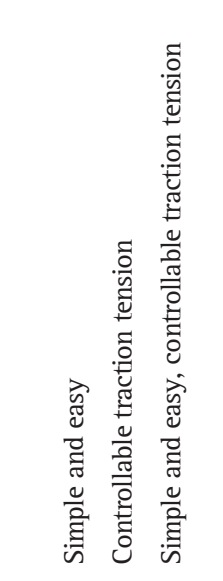

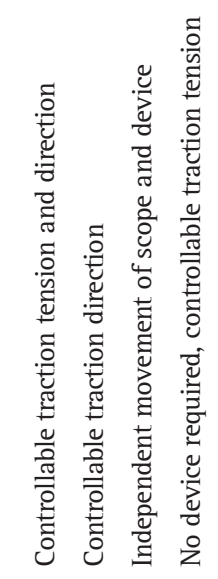

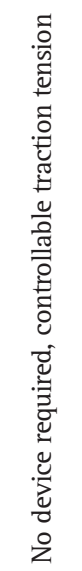

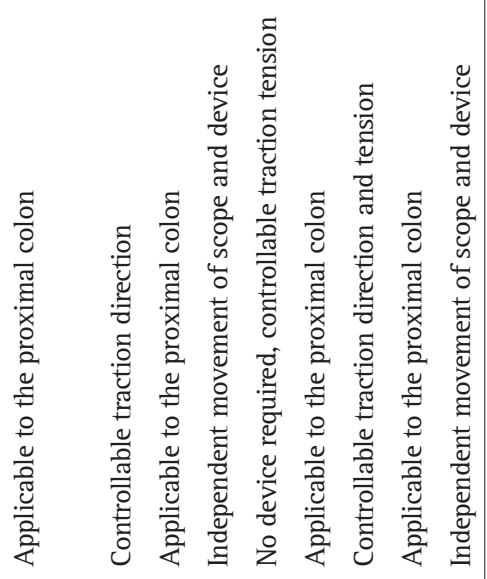

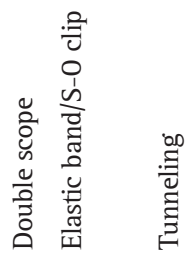

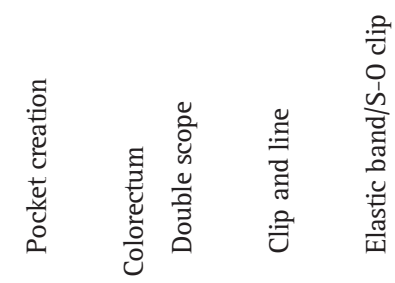

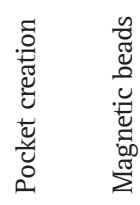




\section{DISCUSSION}

Over the recent years, several traction methods have been applied to facilitate technically demanding ESD. To the best of our knowledge, this is the first review article summarizing and providing an overview of the efficacy of ESD traction techniques according to the organ systems. Five articles of traction methods in the esophagus, 13 in the stomach, and 12 in the colon and rectum were included.

In esophageal ESD, clip line traction was commonly used and shown to significantly reduce the procedural time in one RCT. Because esophagus is a straight tube with little diversity, invariably traction can be applied proximally and maintained until the end of the procedure regardless of the lesion size and location. Additionally, submucosal tunneling technique allows a stable scope position inside the tunnel while providing sufficient traction in the straight lumen of the esophagus. This enables faster submucosal dissection as demonstrated by the two retrospective studies. Moreover, muscle injury was less likely to occur in both the clip line traction and tunneling techniques.

In gastric ESD, there was no significant difference in the procedural time between traction-assisted ESD and conventional ESD in the two RCTs. Gastric ESD is considered to be technically less demanding than esophageal and colorectal ESD, because stomach has a wider working space and the muscle layer is much thicker than that of esophagus and colon. Basic traction technique using gravity or endoscopic cap may provide adequate traction, and clip line traction is shown to be effective only for challenging locations such as the greater curvature of the upper gastric body as shown by Yoshida et al..$^{33}$ Based on the results, routine use of traction device and strategy is unnecessary and selective use is indicated.

Although standard clip line traction is effective in ESD of upper gastrointestinal tract, it is not feasible during colonic ESD because of the need to withdraw and reinsert the colonoscopes. Thus, some modified clip line traction and the unique S-0 clip, which do not interfere with endoscope maneuverability, are more prevalent and both have been shown to be effective in a few RCTs. In addition, PCM is advantageous in maintaining tissue traction during colorectal ESD. Preferred traction methods can be selected depending on the tumor location. In terms of all the studies to date, there are currently no head to head comparisons between the traction techniques.

Advantages and disadvantages of traction methods are shown in Table 4. Ideally, a systematic data analysis was desirable, however, it was very difficult to analyze the entire data and perform a meta-analysis owing to several large heterogeneities of the inclusion criteria of the lesion as well as traction devices and techniques among studies. Further prospective studies are warranted to confirm the evidence of traction-assisted ESD.

\section{CONCLUSIONS}

This article systematically reviewed comparative studies to investigate the efficacy of current traction devices and strategy. Although the effectiveness is dependent on the organ and tumor location, traction techniques facilitate ESD procedures mainly in reducing the procedural time and or dissection time overall.

\section{CONFLICTS OF INTEREST}

No potential conflict of interest relevant to this article was reported.

\section{AUTHOR CONTRIBUTIONS}

Study concept and design: S.A. Data acquisition and interpretation: S.A., S.Y.S.W., M.E. Drafting of the manuscript: S.A., S.Y.S.W., M.E. Critical revision of the manuscript for important intellectual content: H.T., M.S., M.Y., S.N., T.S., H.S., S.Y., T.M., I.O., Y.S. Final approval of the manuscript: I.O., Y.S.

\section{ORCID}

Seiichiro Abe

Shih Yea Sylvia Wu

Mai Ego

Hiroyuki Takamaru

Masau Sekiguchi

Masayoshi Yamada

Satoru Nonaka

Taku Sakamoto

Haruhisa Suzuki

Shigetaka Yoshinaga

Takahisa Matsuda

Ichiro Oda

Yutaka Saito https://orcid.org/0000-0002-2736-6921 https://orcid.org/0000-0002-1679-682X https://orcid.org/0000-0002-3620-0907 https://orcid.org/0000-0002-7019-6331 https://orcid.org/0000-0001-6253-6896 https://orcid.org/0000-0003-3979-5560 https://orcid.org/0000-0002-0925-9137 https://orcid.org/0000-0002-0239-4977 https://orcid.org/0000-0003-2284-0943 https://orcid.org/0000-0002-2368-878X https://orcid.org/0000-0002-9244-2820 https://orcid.org/0000-0001-5252-4197 https://orcid.org/0000-0003-2296-8373

\section{REFERENCES}

1. Oda I, Saito D, Tada M, et al. A multicenter retrospective study of endoscopic resection for early gastric cancer. Gastric Cancer 2006;9:262-270.

2. Oyama T, Tomori A, Hotta K, et al. Endoscopic submucosal dissection of early esophageal cancer. Clin Gastroenterol Hepatol 2005;3(7 Suppl 1):S67-S70.

3. Saito Y, Uraoka T, Yamaguchi Y, et al. A prospective, multicenter study of 1111 colorectal endoscopic submucosal dissections (with video). Gastrointest Endosc 2010;72:1217-1225.

4. Ono H, Yao K, Fujishiro M, et al. Guidelines for endoscopic submucosal dissection and endoscopic mucosal resection for early gastric cancer. Dig Endosc 2016;28:3-15.

5. Suzuki H, Takizawa K, Hirasawa T, et al. Short-term outcomes of 
multicenter prospective cohort study of gastric endoscopic resection: 'Real-world evidence' in Japan. Dig Endosc 2019;31:30-39.

6. Tanaka S, Kashida H, Saito Y, et al. JGES guidelines for colorectal endoscopic submucosal dissection/endoscopic mucosal resection. Dig Endosc 2015;27:417-434.

7. Bhatt A, Abe S, Kumaravel A, et al. Video-based supervision for training of endoscopic submucosal dissection. Endoscopy 2016;48:711-716.

8. Draganov PV, Coman RM, Gotoda T. Training for complex endoscopic procedures: how to incorporate endoscopic submucosal dissection skills in the West? Expert Rev Gastroenterol Hepatol 2014;8:119-121.

9. Pimentel-Nunes P, Dinis-Ribeiro M, Ponchon T, et al. Endoscopic submucosal dissection: European Society of Gastrointestinal Endoscopy (ESGE) Guideline. Endoscopy 2015;47:829-854.

10. Kondo H, Gotoda T, Ono H, et al. Percutaneous traction-assisted EMR by using an insulation-tipped electrosurgical knife for early stage gastric cancer. Gastrointest Endosc 2004;59:284-288.

11. Kobayashi T, Gotohda T, Tamakawa K, Ueda H, Kakizoe T. Magnetic anchor for more effective endoscopic mucosal resection. Jpn J Clin Oncol 2004;34:118-123.

12. Saito Y, Emura F, Matsuda T, et al. A new sinker-assisted endoscopic submucosal dissection for colorectal cancer. Gastrointest Endosc 2005;62:297-301.

13. Abe S, Oda I, Suzuki H, Yoshinaga S, Saito Y. Insulated tip knife tunneling technique with clip line traction for safe endoscopic submucosal dissection of large circumferential esophageal cancer. VideoGIE 2017;2:342-345.

14. Ota M, Nakamura T, Hayashi $\mathrm{K}$, et al. Usefulness of clip traction in the early phase of esophageal endoscopic submucosal dissection. Dig Endosc 2012;24:315-318.

15. Koike Y, Hirasawa D, Fujita N, et al. Usefulness of the threadtraction method in esophageal endoscopic submucosal dissection: randomized controlled trial. Dig Endosc 2015;27:303-309.

16. Xie X, Bai JY, Fan CQ, et al. Application of clip traction in endoscopic submucosal dissection to the treatment of early esophageal carcinoma and precancerous lesions. Surg Endosc 2017;31:462468.

17. Zhang W, Zhai Y, Chai N, et al. Endoscopic submucosal tunnel dissection and endoscopic submucosal dissection for large superficial esophageal squamous cell neoplasm: efficacy and safety study to guide future practice. Surg Endosc 2018;32:2814-2821.

18. Huang R, Cai H, Zhao X, et al. Efficacy and safety of endoscopic submucosal tunnel dissection for superficial esophageal squamous cell carcinoma: a propensity score matching analysis. Gastrointest Endosc 2017;86:831-838.

19. Oyama T. Counter traction makes endoscopic submucosal dissection easier. Clin Endosc 2012;45:375-378.

20. Zhai YQ, Li HK, Linghu EQ. Endoscopic submucosal tunnel dissection for large superficial esophageal squamous cell neoplasms. World J Gastroenterol 2016;22:435-445.

21. Li P, Ma B, Gong S, Zhang X, Li W. Endoscopic submucosal tun- nel dissection for superficial esophageal neoplastic lesions: a metaanalysis. Surg Endosc 2020;34:1214-1223.

22. Ahn JY, Choi KD, Lee JH, et al. Is transnasal endoscope-assisted endoscopic submucosal dissection for gastric neoplasm useful in training beginners? A prospective randomized trial. Surg Endosc 2013;27:1158-1165.

23. Feng X, Linghu E, Chai N, et al. Endoscopic submucosal tunnel dissection for large gastric neoplastic lesions: a case-matched controlled study. Gastroenterol Res Pract 2018;2018:1419369.

24. Harada H, Murakami D, Suehiro S, et al. Water-pocket endoscopic submucosal dissection for superficial gastric neoplasms (with video). Gastrointest Endosc 2018;88:253-260.

25. Hashimoto R, Hirasawa D, Iwaki T, et al. Usefulness of the S-0 clip for gastric endoscopic submucosal dissection (with video). Surg Endosc 2018;32:908-914.

26. Higuchi K, Tanabe S, Azuma M, et al. Double-endoscope endoscopic submucosal dissection for the treatment of early gastric cancer accompanied by an ulcer scar (with video). Gastrointest Endosc 2013;78:266-273.

27. Hijikata Y, Ogasawara N, Sasaki M, et al. Endoscopic submucosal dissection with sheath-assisted counter traction using a novel sheath for early gastric cancers. Hepatogastroenterology 2012;59:353-356.

28. Matsumoto K, Nagahara A, Ueyama H, et al. Development and clinical usability of a new traction device "medical ring" for endoscopic submucosal dissection of early gastric cancer. Surg Endosc 2013;27:3444-3451.

29. Noda H, Ogasawara N, Koshino A, et al. Thread-traction with a sheath of polypectomy snare facilitates endoscopic submucosal dissection of early gastric cancers. Gastroenterol Res Pract 2016;2016:9415497.

30. Okamoto K, Okamura S, Muguruma N, et al. Endoscopic submucosal dissection for early gastric cancer using a cross-counter technique. Surg Endosc 2012;26:3676-3681.

31. Suzuki S, Gotoda T, Kobayashi Y, et al. Usefulness of a traction method using dental floss and a hemoclip for gastric endoscopic submucosal dissection: a propensity score matching analysis (with videos). Gastrointest Endosc 2016;83:337-346.

32. Yoshida M, Takizawa K, Ono H, et al. Efficacy of endoscopic submucosal dissection with dental floss clip traction for gastric epithelial neoplasia: a pilot study (with video). Surg Endosc 2016;30:3100-3106.

33. Yoshida M, Takizawa K, Suzuki S, et al. Conventional versus traction-assisted endoscopic submucosal dissection for gastric neoplasms: a multicenter, randomized controlled trial (with video). Gastrointest Endosc 2018;87:1231-1240.

34. Zhang X, Shi D, Yu Z, et al. A multicenter retrospective study of endoscopic submucosal tunnel dissection for large lesser gastric curvature superficial neoplasms. Surg Endosc 2019;33:1910-1919.

35. Saito Y, Otake Y, Sakamoto T, et al. Indications for and technical aspects of colorectal endoscopic submucosal dissection. Gut Liver 2013;7:263-269. 
36. Uraoka T, Ishikawa S, Kato J, et al. Advantages of using thin endoscope-assisted endoscopic submucosal dissection technique for large colorectal tumors. Dig Endosc 2010;22:186-191.

37. Okamoto K, Muguruma N, Kitamura S, Kimura T, Takayama T. Endoscopic submucosal dissection for large colorectal tumors using a cross-counter technique and a novel large-diameter balloon overtube. Dig Endosc 2012;24 Suppl 1:96-99.

38. Ritsuno H, Sakamoto N, Osada T, et al. Prospective clinical trial of traction device-assisted endoscopic submucosal dissection of large superficial colorectal tumors using the S-0 clip. Surg Endosc 2014;28:3143-3149.

39. Yamada S, Doyama H, Ota R, et al. Impact of the clip and snare method using the prelooping technique for colorectal endoscopic submucosal dissection. Endoscopy 2016;48:281-285.

40. Sakamoto H, Hayashi Y, Miura Y, et al. Pocket-creation method facilitates endoscopic submucosal dissection of colorectal laterally spreading tumors, non-granular type. Endosc Int Open 2017;5:E123-E129.

41. Mori H, Kobara H, Nishiyama N, Fujihara S, Matsunaga T, Masaki T. Novel effective and repeatedly available ring-thread counter traction for safer colorectal endoscopic submucosal dissection. Surg Endosc 2017;31:3040-3047.

42. Kanamori A, Nakano M, Kondo M, et al. Clinical effectiveness of the pocket-creation method for colorectal endoscopic submucosal dissection. Endosc Int Open 2017;12:E1299-E1305.

43. Yoshida N, Naito Y, Yasuda R, et al. The efficacy of the pocketcreation method for cases with severe fibrosis in colorectal endoscopic submucosal dissection. Endosc Int Open 2018;6:E975-E983.

44. Yamasaki Y, Takeuchi Y, Uedo N, et al. Efficacy of traction-assisted colorectal endoscopic submucosal dissection using a clip-andthread technique: a prospective randomized study. Dig Endosc
2018;30:467-476.

45. Takezawa T, Hayashi Y, Shinozaki S, et al. The pocket-creation method facilitates colonic endoscopic submucosal dissection (with video). Gastrointest Endosc 2019;89:1045-1053.

46. Harada H, Nakahara R, Murakami D, et al. Saline-pocket endoscopic submucosal dissection for superficial colorectal neoplasms: a randomized controlled trial (with video). Gastrointest Endosc 2019;90:278-287.

47. Ye L, Yuan X, Pang M, et al. Magnetic bead-assisted endoscopic submucosal dissection: a gravity-based traction method for treating large superficial colorectal tumors. Surg Endosc 2019;33:20342041.

48. Yamasaki Y, Takeuchi Y, Hanaoka N, et al. A novel traction method using an endoclip attached to a nylon string during colonic endoscopic submucosal dissection. Endoscopy 2015;47 Suppl 1 UCTN:E238-E239.

49. Sakamoto N, Osada T, Shibuya T, et al. Endoscopic submucosal dissection of large colorectal tumors by using a novel springaction S-0 clip for traction (with video). Gastrointest Endosc 2009;69:1370-1374.

50. Sakamoto N, Osada T, Shibuya T, et al. The facilitation of a new traction device (S-O clip) assisting endoscopic submucosal dissection for superficial colorectal neoplasms. Endoscopy 2008;40 Suppl 2:E94-E95.

51. Hayashi Y, Sunada K, Takahashi H, et al. Pocket-creation method of endoscopic submucosal dissection to achieve en bloc resection of giant colorectal subpedunculated neoplastic lesions. Endoscopy 2014;46 Suppl 1 UCTN:E421-E422.

52. Hayashi Y, Miura Y, Yamamoto H. Pocket-creation method for the safe, reliable, and efficient endoscopic submucosal dissection of colorectal lateral spreading tumors. Dig Endosc 2015;27:534-535. 